\title{
RISK FACTORS FOR HYPOTENSION AFTER SPINAL ANESTHESIA
}

\author{
Marija Jović1, Biljana Stošić ${ }^{2,3}$, Nebojša Videnović ${ }^{4}$ \\ Rade Mitić ${ }^{1}$, Danijela Stanković ${ }^{5}$
}

Department of Anesthesiology and Reanimatology, General Hospital Leskovac, Serbia ${ }^{1}$

University of Niš, Faculty of Medicine, Niš, Serbia²

Anesthesiology Center, Clinical Center Niš, Serbia ${ }^{3}$

Department of Anesthesiology and Reanimatology,

Clinical Hospital Center Priština - Gracanica, Faculty of Medicine,

the University of Priština with the headquartered in Kosovska Mitrovica ${ }^{4}$

Department of Anesthesiology and Reanimatology,

Health Center Negotin ${ }^{5}$

Contact: Marija Jović

Đorđa Andrejevića Kuna 39, 16000 Leskovac

E-mail: mladenovicmarija@yahoo.com

Spinal anesthesia is widely used in everyday clinical work. Hypotension is one of the most frequent side effects of spinal anesthesia. Knowledge of the risk factors for hypotension is useful in increasing the vigilance in those patients most at risk for hypotension, enabling a timely therapeutic intervention. The aim of this study was to identify the factors associated with hypotension after spinal anesthesia, using the data of a group of patients who underwent elective surgery. The study involved 89 patients, classified by the American Society of Anesthesia (ASA) as of physical status I to III, who were scheduled to have elective surgery with spinal anesthesia. Patients were allocated to groups depending on their age, gender, chronic alcohol intake, preoperative history of hypertension or hypotension, vascular disease, endocrine diseases, ASA physical status, Lee's index and type of surgery. Hypotension was encountered in 29 (33\%) patients. One patient $(3 \%)$ had a history of chronic alcohol abuse. A large number of patients had physical status II as classified by the ASA, 22 (77\%) and by the Lee's index, 28 (97\%) patients were in the group with a low cardiac risk. The most frequent incidence was during an orthopedic surgery $(77 \%)$. The knowledge of these risk factors should be useful in suggesting the use of alternative methods of spinal anesthesia, such as titrated continuous or small-dose spinal anesthesia. Acta Medica Medianae 2017;56(2):105-110.

Key words: spinal anesthesia, hypotension, risk factors 